\title{
Lemurs in Captivity
}

\section{By Jeremy J. Mallinson}

M ORE than half the species and subspecies of the Malagasy prosimians - the lemurs and the aye-aye - one of the most interesting animal groups in the world, are listed in the IUCN Red Data Book as 'rare and endangered'. Possibly not more than 50 aye-ayes remain in the wild. As reported in ORYX April 1967, Dr J. J. Petter and M. Peyriras have had remarkable success in transferring nine aye-ayes to the newly created island reserve of Nossi Mangabé, off the coast of Madagascar, in an eleventh-hour attempt to save them, and so long as they can be protected in their natural habitat it would be unwise, with numbers so low, to move them to another country.

The requirements of lemurs in captivity have hardly been considered until recently, and animals that need a lot of exercise, fresh air and sunshine have been confined to small heated indoors accommodation, and kept singly or in pairs; as a result some have become excessively fat and incapable of breeding. The need to study the requirements of individual species is of prime importance. Social animals must be kept in a social group, with its subsequent troop activity, and provided with sufficient space to live a normal healthy life; the advice of field scientists on the lemurs' nutritional, social and territorial requirements is essential. Copenhagen and Frankfurt Zoos have had excellent results in keeping lemurs in open-air enclosures. $M$ Georges Basilewsky breeds the ringtailed and mongoose lemurs regularly at Cros-de-Cagnes, where they live throughout the year in open-air cages with only partial cover from the rain, and are accustomed to the winter temperatures falling several degrees below zero.

Lemurs are reasonably successful in captivity,

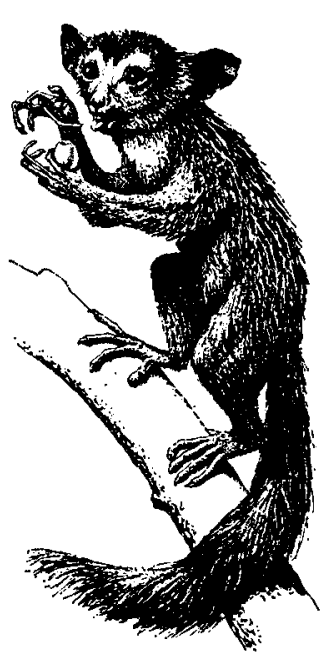

The aye-aye, rarest of the Madagascar lemurs but births are relatively rare with the exception of the ring-tailed lemur, of which 114 young have been reared in 38 zoos between 1959 and 1965 . Nine other lemur species have been bred in the same period: brown lemur 33 ; mongoose 13 ; black 10; mouse 10 ; red-fronted 5 ; white-fronted 2 ; ruffed 2; collared 1, and greater dwarf $1-77$ infants in 29 zoos (International Zoo Year Book). The Zoological Society of San Diego in 1963 explored the possibilities of captive breeding as a means of conserving Madagascar wildlife, and they have pairs of the rare white-fronted and redfronted lemurs in their collection, (Zoonooz Oct. 67); the Jersey Wildlife Preservation Trust also intends to specialise in Madagascar fauna.

Jeremy Mallinson is Deputy Director of the Jersey Zoological Park. 
Dr Petter, with the co-operation of the Madagascan Government, is working in close conjunction with IUCN, co-ordinating and implementing conservation measures in Madagascar. With the recently introduced $£ 100$ levy on the export of lemurs from Madagascar, it has become more difficult to get animals with which to build up groups in captivity, so it is more than ever important for zoos to make the best possible use of those they already have and to co-operate in building up potential breeding colonies for a permanent breeding programme, with stud books of the rarer species. If the Malagasy reserves are subjected to further degradation and are unable to support their wildlife, zoos could play an important part in ensuring the survival of this unique fauna.

The drawing of the aye-aye is reproduced from The Land and Wildlife of Africa, by Archie Carr, in the Life Nature Library, by kind permission of the publishers.

\section{Primate News}

MORE than 60,000 primates were taken for research in the USA in 1966 according to the Laboratory Primate Newsletter. Of these only 4070 were bred by the research institutions; 58,173 were acquired through dealers, including nearly 300 apes, mostly chimpanzees. Over 50,000 were Old World monkeys, mostly rhesus and cynomolgus, macaques and vervets; more than 11,000 from the New World were mostly squirrel monkeys. A primate biology programme covering both education and research has been started at the Smithsonian Institution in Washington under the direction of J. R. Napier, who will also have an office in London. Dr Napier is also president of the newly founded Primate Society in London, for promoting research in primate biology, of which the Hon Secretary is Richard P. Michael, Institute of Psychiatry, 3 de Crespigny Park, London SE5.

A survey of rhesus monkeys in northern India showed a substantial reduction in numbers in the villages and an increase in the towns, with a considerable increase in the proportion of juveniles in both villages and towns. In their report on the survey, published in the February Journal of Animal Ecology, the two scientists concerned, Charles H. Southwick and M. Rafiq Siddiqi, attribute the changes to the fact that trappers do not work in towns because of the danger of diseased animals, and that the town monkeys have become commensals of man, like rats, living on food scraps. Being highly adaptable and aggressive the rhesus monkey, they say, will continue to survive, but increasing urbanisation will not make for healthy or valuable animals.

As a result of the findings in a WWF survey on the vervet monkey in Kenya, undertaken because of the large numbers being trapped by dealers for medical research and polio vaccine purposes, the Kenya government has stopped all trapping of vervets pending possible new regulations. The government has also banned the export of wild animals trapped in Kenya, except for those destined for public (not private) zoos and recognised research bodiès.

\section{Israeli Field Centre}

With the aid of a grant from the World Wildlife Fund, a Field Study Centre for Conservation has been opened on Mt. Meiron, in Israel, the fifth of a chain of centres established by the Society for the Protection of Nature in Israel. 